\title{
Finite Element Analysis of Contact Pressures between Seat Cushion and Human Buttock-Thigh Tissue
}

\author{
Chak Yin Tang, Wai Chan, Chi Pont Tsui \\ ${ }^{1}$ Department of Industrial and Systems Engineering, Hong Kong Polytechnic University, \\ Hong Kong, China \\ E-mail:mfgary@inet.polyu.edu.hk \\ Received May 19, 2010; revised July 21, 2010; accepted August 6, 2010
}

\begin{abstract}
Unrelieved pressure on load-bearing muscle tissues of humans can produce pressure ulcers. In a seated upright posture, the highest pressures occur inferior to the ischial tuberosities (ITs). Moreover, the vibration can initiate the development of pressure ulcer. Therefore, the seat cushion is not only used to lower the maximum seating pressure on buttocks but also minimize the transmission of vibration to human body. The purpose of this study was to investigate the effects of varying vertical vibration frequencies on seat-interface contact pressure during sitting on three different seat cushions by using a finite element modeling approach. A simplified two-dimensional human buttock-thigh model was developed to simulate the mechanical response of the muscle of buttocks and thigh under vertical vibration. Static and vibrational loads with five different frequencies of $0.1,1,10,30$ and $50 \mathrm{~Hz}$ and the same amplitude of $3 \mathrm{~mm}$ were applied to different seat cushions. The result showed that the "SAF 6060" seat cushion with both hyperelastic and viscoelastic behaviors could be effective in reducing the amplitude of varying maximum contact pressure, especially for the frequency of 10-20 Hz. This method could help in design of seat cushions with appropriate material properties and shape so as to reduce vibrations transmitted to human body at a certain frequency range.
\end{abstract}

Keywords: Finite Element Analysis, Seat Cushion, Vibration, Buttock-Thigh

\section{Introduction}

Static seating comfort is important for drivers and wheelchair users. Seat-interface pressure distribution has been used as an objective measure for discomfort prediction [1]. Experimental methods could find the interface pressure between human body and seat. However, it could not provide the information about subcutaneous stress and deformations of soft tissues. For drivers and wheelchair users who have sat for a long time, they could be associated with an increased risk of pressure ulcers [2]. Moreover, severe pressure ulcer initiates in muscle tissue overlying a bony prominence (ischial tuberosity) and progresses outwards through fat and skin, giving rise to the subcutaneous stress [3,4]. Many researchers conducted two-dimensional (2D) and three-dimensional (3D) finite element analyses to investigate the subcutaneous stress [1,5-12]. Ragan et al. determined the effects of the thickness of polymer foam wheelchair cushions on subcutaneous pressures during seating by using a finite element approach [8]. It was found that seat-interface pres- sures were a good indicator for reducing the subcutaneous stress.

Shocks normal to the seat cushions and shear stresses could initiate the development of pressure ulcer $[13,14]$. Following the directive 2002/44/EC of the European Parliament, manufacturers of seat cushions were required to limit vibration exposure to users. Wu et al., [15] found that the maximum ischium pressure and the effective contact area on a soft seat occur near resonant frequency of the coupled human-seated system $(2.5-3.0 \mathrm{~Hz})$, and generally increased considerably with increase in the magnitude of vibration excitation. DiGiovine et al., [16] discussed that the application of the appropriate seating system may reduce the amount of whole-body vibration experienced by an individual during manual wheelchair propulsion, They also suggested the manufacturers should concentrate on designing seat cushions that shift the resonant frequency away from the range of frequencies most sensitive to humans during whole-body vibration $(4-12.5 \mathrm{~Hz})$ as defined in ISO 2631-1:1997 [17].

Owing to these reasons, many researchers developed a 
biomechanical model of human body for investigating the dynamic response to vertical vibrations. Verver et al., [18] developed a finite element model for the human body using MADYMO while Siefert et al. [9] used CASIMIR for model creation. However, for their models, only hyperelastic behavior was used to describe the seat cushion and human soft tissue but their viscoelastic properties were not considered. Kitazaki and Griffin [19] used beam, spring and mass elements to model a 2D human model including the spine, viscera, head, pelvis and buttocks tissue. This model was good for estimating the transmission capability from vertical seat motion to vertical spinal motion. Other methods such as lumped parameter model [20,21] and finite segment model [22] were also used to evaluate the whole-body vibration . However, these two methods could not present realistic human geometry. Other researchers experimentally determined if seat cushions of a selected wheelchair could minimize the transmission of vibrations to users $[16,23$, 24].

The main goal of our study was to investigate the effects of vertical vibration on subcutaneous stress of buttocks sitting on three different seat cushions by using a finite element modeling approach. The simplified buttock-thigh model was developed for the analysis. The hyperelastic and viscoelastic properties were used to describe the mechanical behaviors of the human soft tissue and seat cushion.

\section{Methodology}

\subsection{Buttock-Thigh Model}

Figure 1 shows the buttock-thigh model consisting of a femur and ischial tuberosity (IT) for representing humans in a sitting posture. It was assumed that a human sit uprightly on the cushion and there was no support on the feet. The total length of the buttock-thigh model was 60 $\mathrm{cm}$ for the male at the fifty-percentile [25]. A circle with a radius of $1 \mathrm{~cm}$ represents the cross section of the IT where supports the body's weight in a sitting position. The distance between the bottom of the IT and the skin was $4 \mathrm{~cm}$ [8]. The thickness of the cushion was set to 8 $\mathrm{cm}$ because Chow and Odell [26] found that the cushion thickness beyond $8 \mathrm{~cm}$ was ineffective in further reducing subcutaneous stress. The distance between the buttockthigh model and the cushion was set to $1 \mathrm{~cm}$ at the beginning step because the buttocks were assumed not to sit on the cushion initially. With the finite element tool ABAQUS, the buttock-thigh model and seat cushion were meshed using 2D plane strain elements as shown in Figure 2.

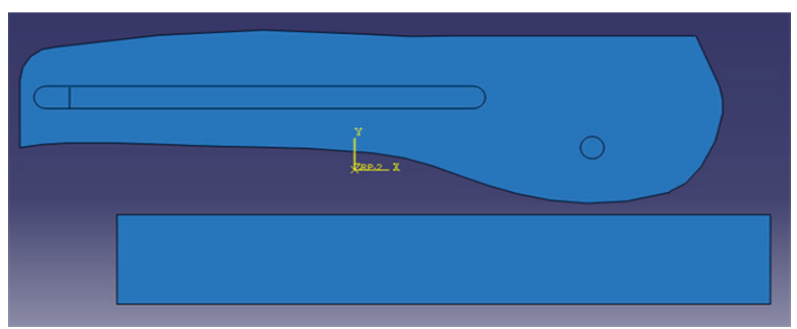

Figure 1. The buttock-thigh model and the cushion.

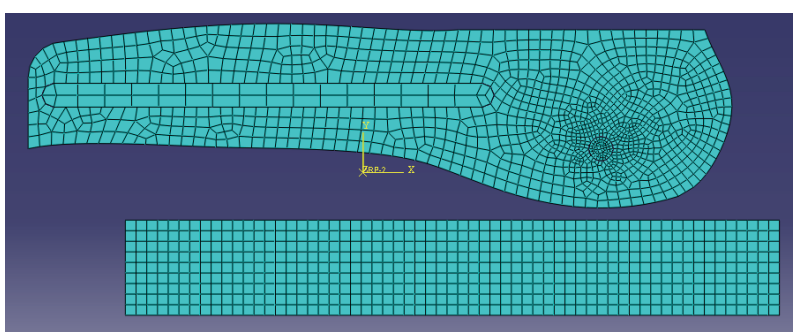

Figure 2. Finite element model of the buttock-thigh model and the cushion.

\subsection{Material Models}

The muscle and seat cushions were assigned different material properties. All bones in the model were defined as rigid bodies, because their stiffness is very high as compared to the muscle and cushion.

\subsubsection{Seat Cushions}

Three different material properties of seat cushions were considered in this study. One of the seat cushions was assumed to be made of SAF 6060 polymer foam with rate-independent hyperelastic and viscoelastic behaviors, which was produced by Foam Partner Fritz Nauer AG. Another two seat cushions were similar to the abovementioned SAF6060 cushion but with a linear elastic response instead of the hyperelastic behavior. The Young moduli of these two cushions were separately set to 15 $\mathrm{kPa}$ (Elastic 15000) and $20 \mathrm{kPa}$ (Elastic 20000), while their Poisson's ratio was 0.3 [27].

The hyperealstic behavior of the seat cushion SAF6060 was represented using a non-linear isotropic compressible hyperelastic soft foam material model or a so-called hyperfoam. The hyperelastic behavior of the foam material is described by the strain energy potential, $U$ in the following form:

$$
U=\sum_{i=1}^{\mathrm{N}} \frac{2 \mu_{i}}{\alpha_{i}^{2}}\left[\hat{\lambda}_{1}^{\alpha_{i}}+\hat{\lambda}_{2}^{\alpha_{i}}+\hat{\lambda}_{3}^{\alpha_{i}}-3+\frac{1}{\beta_{i}}\left(\left(J^{e l}\right)^{-\alpha_{i} \beta_{i}}-1\right)\right]
$$

where $N$ is the order of the strain energy potential, $\mu_{i}$, $\alpha_{i}$ and $\beta_{i}$ are the temperature-dependent material parameters; $\hat{\lambda}_{i}=\left(J^{t h}\right)^{-\frac{1}{3}} \lambda_{i}, \hat{\lambda}_{1} \hat{\lambda}_{2} \hat{\lambda}_{3}=J^{e l}$ and $\lambda_{i}$ are the principal stretches. $J^{e l}$ is the ratio of elastic-deformation to 
volume-change and $J^{\text {th }}$ is the ratio of the thermal-strain to volume-change. The coefficients $\mu_{i}$ are related to the initial shear modulus while the coefficient $\beta_{i}$ determines the degree of compressibility and is related to the Poisson's ratio [28]. In the present work, polyurethane soft foam parameters determined by Schrodt et al. [29] from uniaxial compression tests were used to define the above-mentioned material parameters for SAF 6060 cushion as listed in Table 1. Moreover, its density was set to $60 \mathrm{~kg} / \mathrm{m}^{3}$ and a second order $(N=2)$ of the strain energy potential was used.

The viscoelastic behavior of the SAF 6060 cushion was defined by using a time-based Prony-series model for the shear modulus only because the time-dependency of bulk modulus is generally not significant [5]. Timedependent shear relaxation modulus $G(t)$ is given by

$$
G(t)=G_{0}-\sum_{i=1}^{N} G_{i}\left(1-e^{-t / \tau_{i}^{G}}\right)
$$

where $\tau_{i}^{G}$ is the relaxation time and $N$ is the order of the Prony series. $G_{0}$ and $G_{i}$ are the instantaneous shear modulus and relative shear modulus, respectively. With reference to the findings by the work of Grujicic et al. [5], the viscoelastic material parameters for the SAF 6060 cushion were defined such that $N=2, G_{1}=0.3003$ and $\tau_{1}=0.010014 \mathrm{~s}$, and $G_{2}=0.1997$ and $\tau_{2}=0.1002 \mathrm{~s}$.

\subsubsection{Muscle}

The muscular portion of the buttock-thigh model was modeled using a non-linear visco-hyperelastic isotropic material model to describe the human soft tissue. The density of soft tissue is $1000 \mathrm{~kg} / \mathrm{m}^{3}$ [30] and hyperelastic portion of the soft tissue is expressed in the form of the polynomial strain energy potential, $W$ :

$$
W=\sum_{i+j=1}^{N} C_{i j}\left(\bar{I}_{1}-3\right)^{i}\left(\bar{I}_{2}-3\right)^{j}+\sum_{i=1}^{N} \frac{1}{D_{i}}\left(J^{e l}-1\right)^{2 i}
$$

where $C_{i j}$ and $D_{i}$ are the material parameters. A higher $N$ value may provide a better fit to the exact solution. However, it may cause numerical difficulty in fitting the material constants and require enough data to cover the entire range of interest of deformation. Therefore a very higher $N$ value is not usually recommended. In the present study, $N=2$ was chosen and the hyperelastic parameters for the muscle model obtained from a URL, http://lyle.smu.edu/ hyao/academics.html\#Research are listed in Table 2. Referring to the work of Tang and Tsui [31], the viscoelastic parameters for the muscle model were set as $G_{1}=0.5, K_{1}=0.5$ and $\tau_{1}=0.8 \mathrm{~s}$.

\subsection{Simulation Set-Up}

In the present study, ABAQUS explicit dynamics analysis has been performed to deal with the dynamic problem.
As this type of analysis uses a consistent large-deformation theory, the cushion and the muscle model could undergo large rotations and deformation. The analysis procedure was implemented by using an explicit integration rule and diagonal element mass matrices. The equations of motion for the body were integrated using the following explicit central-difference integration rule:

$$
\dot{u}_{\left(i+\frac{1}{2}\right)}^{N}=\dot{u}_{\left(i-\frac{1}{2}\right)}^{N}+\frac{\Delta t_{(i+1)}+\Delta t_{i}}{2} \ddot{u}_{(i)}^{N}
$$

and

$$
u_{\left(i+\frac{1}{2}\right)}^{N}=u_{(i)}^{N}+\Delta t_{(i+1)} \dot{u}_{\left(i+\frac{1}{2}\right)}^{N}
$$

where $u^{N}$ is a degree of freedom (a displacement or rotation component) and the subscript $i$ refers to the increment number in an explicit dynamics step. The central-difference integration operator is explicit such that the kinematic state is advanced using known values of $\dot{u}_{(i+1 / 2)}^{N}$ and $\ddot{u}_{(i)}^{N}$ from the previous increment [28].

\subsection{Interaction between the Buttock-Thigh Model and Cushion}

In this work, it was assumed that the human sit on the cushion and then the vertical vibration was applied onto the bottom of the cushion. The loading was applied to the model due to the weight of the human, such that a gravity-based body force was used to prescribe the loading. The interaction between the buttock-thigh model and the cushion was analyzed in ABAQUS/Explicit using a penalty contact method with finite-sliding. Surface-to-surface contact with a coefficient of friction of 0.5 [5] was used to define the contact pair between the buttock-thigh model and cushion. The outer surface of the buttockthigh model was defined as the "master surface" which has a larger surface and higher stiffness, while the surface of the cushion was defined as the "slave surface" which is softer and has smaller surface than that of the buttock-thigh model. The surfaces between the bone and muscle were tied together so that there was no relative motion between them.

Table 1. Hyperelastic material parameters for the SAF6060 cushion.

\begin{tabular}{lccccc}
\hline$\mu_{1}[\mathrm{MPa}]$ & $\alpha_{1}$ & $\beta_{1}$ & $\mu_{2}[\mathrm{MPa}]$ & $\alpha_{2}$ & $\beta_{2}$ \\
\hline 0.481 & 0.198 & 0.145 & $0.36 \times 10^{-2}$ & $0.198 \times 10^{2}$ & $0.65 \times 10^{-2}$ \\
$\times 10^{-2}$ & $\times 10^{2}$ & $\times 10^{-1}$ & 0.36 & \\
\hline
\end{tabular}

Table 2. Hyperelastic material parameters for the muscle model (All values in MPa).

\begin{tabular}{lllllll}
\hline$C_{10}$ & $C_{01}$ & $C_{20}$ & $C_{11}$ & $C_{02}$ & $D_{1}$ & $D_{2}$ \\
\hline 0.08556 & -0.05841 & 0.039 & -0.02319 & 0.00851 & 3.65273 & 0 \\
\hline
\end{tabular}




\subsection{Loading and Boundary Conditions}

According to fifty-percentile male body segment masses [25], the total weight is $80.4 \mathrm{~kg}$, including $54.5 \mathrm{~kg}$ of the upper body and $25.9 \mathrm{~kg}$ of the lower body. The current model represented only one side of the body so that the mass assigned to the model should be halved. Thus, the weight of the upper body on the iscahial tuberosity was set as $27.3 \mathrm{~kg}$ while the weight of lower leg on the femur was set as $4.5 \mathrm{~kg}$. Figure 3 shows the positions of the assigned masses. It was assumed that the cushion was placed on a rigid surface so that the bottom surface of the cushion was restricted to move in all directions. Moreover, the upper surface of the buttock-thigh model was limited to move in $X$-direction only.

The analyses were performed in two steps. In the first step, the buttock-thigh model moved to sit on the seat cushion due to the gravity load $\left(9.81 \mathrm{~ms}^{-2}\right)$. After 15 seconds, there followed a second step in which a vertical vibration in the form of harmonic motion was applied onto the bottom of the cushion. The periodic definition method was used to define the amplitude. The frequencies of the vibration were chosen to be $0.1,1,10,20$ and $50 \mathrm{~Hz}$ which are the frequencies generated mostly in our life according to Table 3 [32]. A vibration amplitude of $3 \mathrm{~mm}$ was applied to the bottom of the cushion. Each vibration case was conducted for 50 cycles (see Table 4).

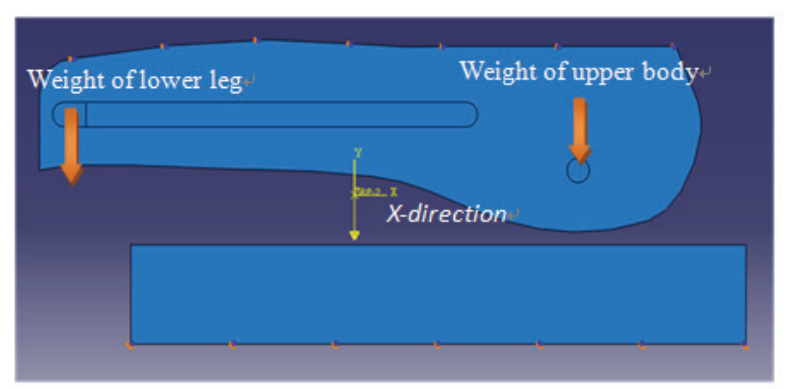

Figure 3. Loading and boundary conditions on the buttockthigh model and cushion.

Table 3. Sensitivity of human systems to vibration.

\begin{tabular}{|c|c|c|c|}
\hline $\begin{array}{l}\text { Frequency } \\
\text { Level }\end{array}$ & $\begin{array}{l}\text { Frequency } \\
\text { range }\end{array}$ & Sensitivity & $\begin{array}{l}\text { Vibration } \\
\text { Generator }\end{array}$ \\
\hline Low & 0 to $1-2 \mathrm{~Hz}$ & Vestibular system & $\begin{array}{l}\text { Ships, } \\
\text { cranes, air- } \\
\text { crafts }\end{array}$ \\
\hline Middle & $\begin{array}{l}2 \text { to } 20-30 \\
\mathrm{~Hz}\end{array}$ & $\begin{array}{l}\text { Biomechanics: body } \\
\text { resonances }\end{array}$ & $\begin{array}{l}\text { Vehicles, } \\
\text { aircrafts }\end{array}$ \\
\hline High & $>20 \mathrm{~Hz}$ & $\begin{array}{l}\text { Somesthetic recep- } \\
\text { tors in muscles, } \\
\text { tendons, skins }\end{array}$ & $\begin{array}{l}\text { Tools, ma- } \\
\text { chinery }\end{array}$ \\
\hline
\end{tabular}

Table 4. Different loading conditions for the simulation.

\begin{tabular}{ccccccc}
\hline & \multicolumn{5}{c}{ Loading } \\
\cline { 2 - 7 } & $\begin{array}{c}\text { Grav } \\
\text { ity }\end{array}$ & $\begin{array}{c}\text { Vertical } \\
\text { vibration } \\
\text { of } 0.1 \\
\mathrm{~Hz}\end{array}$ & $\begin{array}{c}\text { Vertical } \\
\text { vibration } \\
\text { of } 1 \mathrm{~Hz}\end{array}$ & $\begin{array}{c}\text { Vertical } \\
\text { of } 10 \mathrm{~Hz}\end{array}$ & $\begin{array}{c}\text { Vertical } \\
\text { vibration } 20 \mathrm{~Hz}\end{array}$ & $\begin{array}{c}\text { Vertical } \\
\text { vibration }\end{array}$ \\
& & $50 \mathrm{~Hz}$ \\
\hline $\begin{array}{c}\text { Duration } \\
\text { (Second) }\end{array}$ & 15 & 500 & 50 & 5 & 2.5 & 1 \\
\hline
\end{tabular}

\section{Results and Discussions}

As the distribution of the contact pressure at the seated human/cushion contact interface is important for determining the seating comfort [5], the maximum contact pressure at three different locations of the three cushions at the frequency of $20 \mathrm{~Hz}$ have been identified as shown in Figure 4. Among them, the SAF 6060 cushion shows the lowest contact pressure at the locations of $\mathrm{A}$ and $\mathrm{B}$. As the location B is under the ichial tuberosities (IT), minimizing the contact pressure at this location means minimizing the stress under IT. It can also be observed from Figure 5 that the maximum von Mises stress near IT using the SAF 6060 cushion is lower than the other two cushions by about $30 \sim 37 \%$ at the same frequency of $20 \mathrm{~Hz}$. Moreover, the SAF 6060 cushion shows lower stress within the buttock especially at the region near the cushion as shown in Figure 6. Therefore, the SAF 6060 cushion is effective in reducing the stress below IT, and also has better pressure distributions at three distinct locations than the other two.

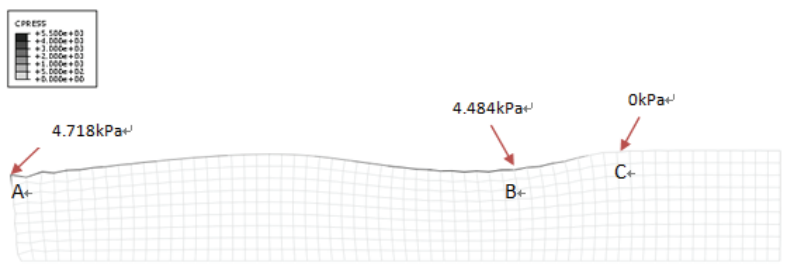

(a)
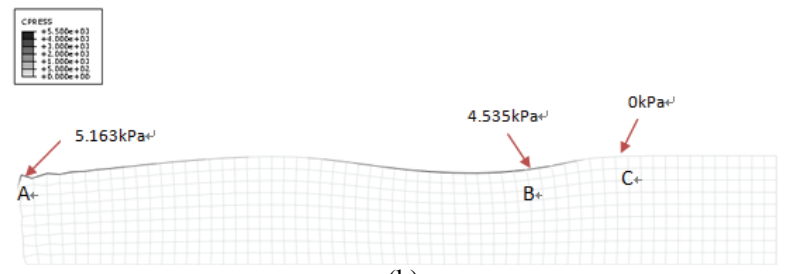

(b)

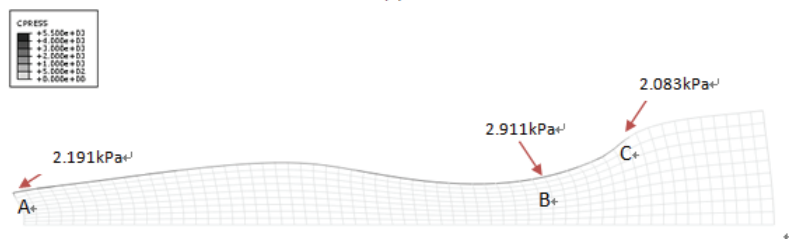

(c)

Figure 4. Maximum contact pressure at the three different locations of the three cushions at the frequency of $20 \mathrm{~Hz}$. (a) Elastic 15000; (b) Elastic 20000 and (c) SAF 6060. 


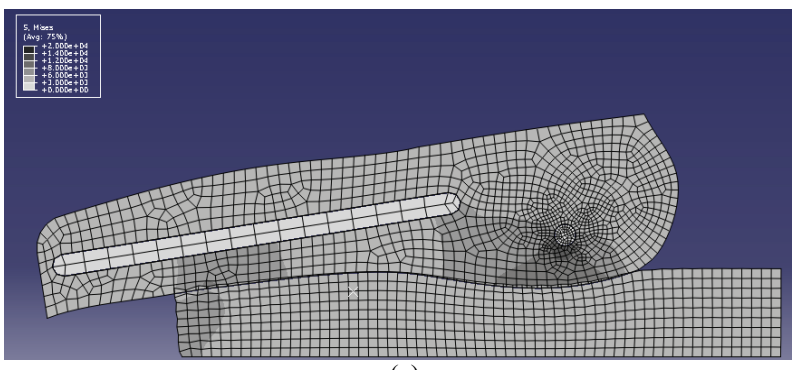

(a)

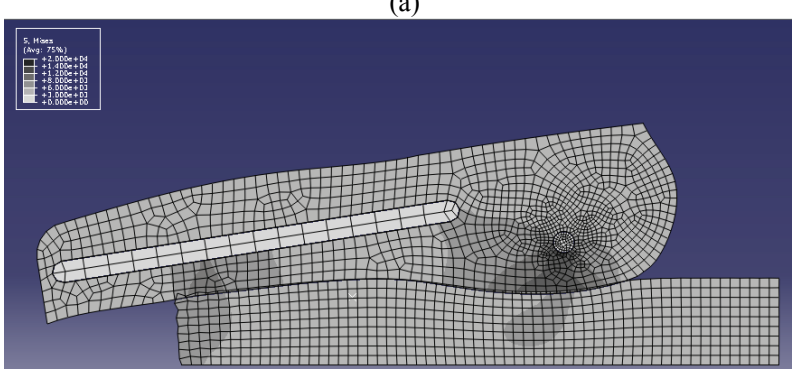

(b)

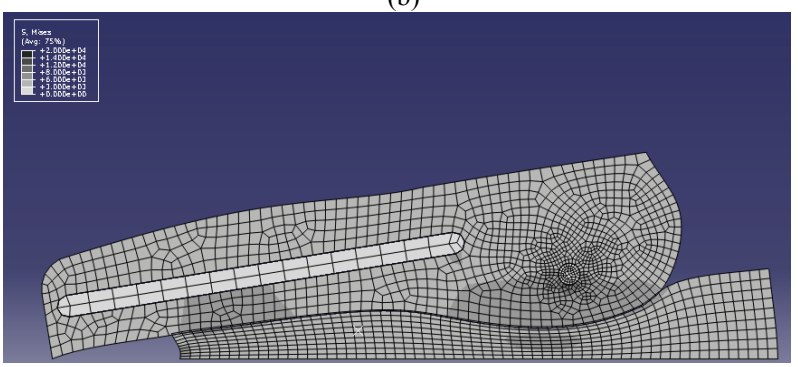

(c)

Figure 5. von Mises stresses distribution within the human body and cushion at the frequency of $20 \mathrm{~Hz}$. (a) Elastic 15000; (b) Elastic 20000 and (c) SAF 6060.

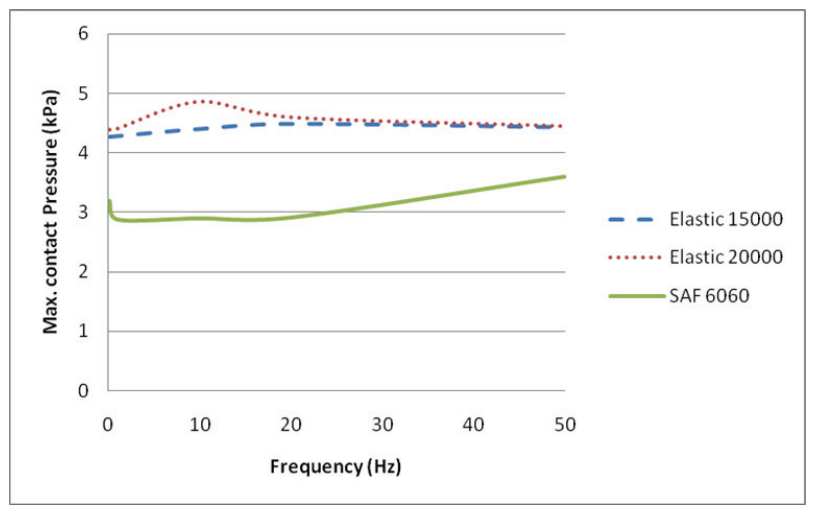

Figure 6. Maximum contact pressure versus frequency.

For a range of frequencies under study, the magnitude of maximum contact pressure in the SAF 6060 cushion is much lower than that of the other two cushions as shown in Figure 6. Figure 7 shows the variation of maximum contact pressure with time for the three different cushions in response to five different frequencies. In Figure 7, the contact pressure generally increases rapidly to reach a maximum for all frequencies and cushions during the first step, because the buttock-thigh model fell quickly onto the cushion due to the gravity.

During the second step, all the three cushions were subjected to a vertical vibration of different frequencies. At the frequency of $0.1 \mathrm{~Hz}$, the responses of all three cushions are slow and do not vary sinusoidally after 15 seconds as shown in Figure 7(a). It can be observed from Figure 7(a) that the maximum contact pressure at the location B for the Elastic 15000 and Elastic 20000 cushions keep increasing with time while that for the SAF 6060 cushion increases with time up to 500 seconds. When the frequency is increased to $1 \mathrm{~Hz}$, there is only a slight change in the maximum contact pressure around 0.02 to $0.04 \mathrm{kPa}$ as shown in Figure 7(b). When the frequency is increased to $10 \mathrm{~Hz}$ or above, the responses of all the cushions become significant after 15 seconds. It is apparent from Figures 7(c) and 7(d) that the amplitude of varying maximum contact pressure for the SAF 6060 cushion at the frequency of $10 \mathrm{~Hz}$ and $20 \mathrm{~Hz}$ is only around $0.15 \mathrm{kPa}$, which is much lower than those of the other two cushions by $63 \sim 85 \%$. At the frequency of 50 $\mathrm{Hz}$, the amplitude for the SAF 6060 cushion has sharply increased to $1.2 \mathrm{kPa}$, which is much higher than those of the other two cushions as shown in Figure 7(e). Therefore, the SAF 6060 cushion is effective in reducing the amplitude of varying maximum contact pressure, especially for the frequency of $10-20 \mathrm{~Hz}$, which belong to the frequency range of vibration generated mostly by vehicles and aircrafts.

For simplification and reducing the amount of CPU time for running the simulation, the 2D model of the buttock-thigh was firstly developed to study mechanical responses in bony prominence of IT and the vibration

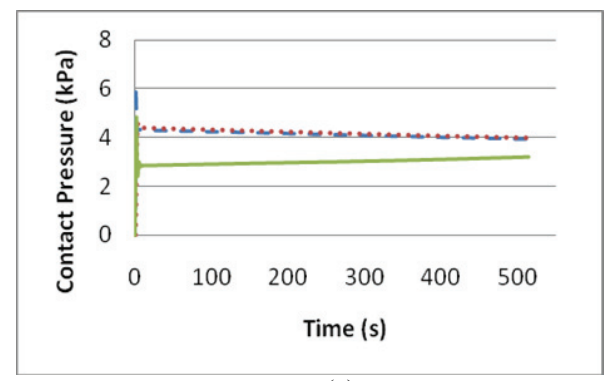

(a)

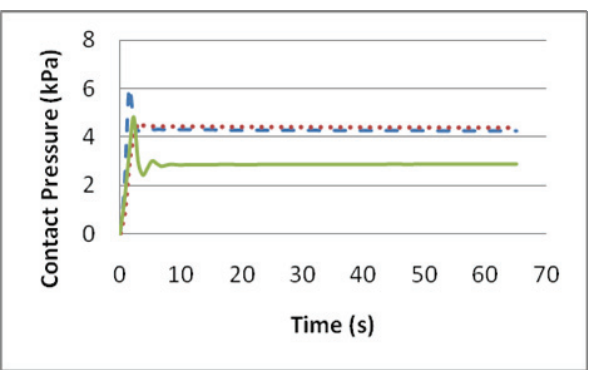

(b) 


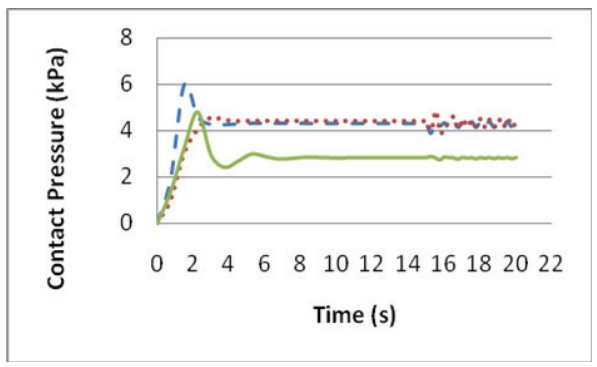

(c)

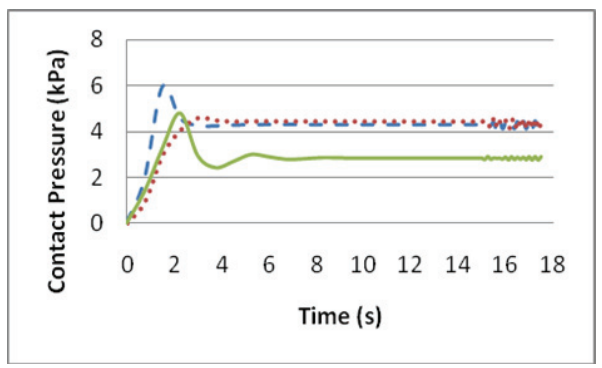

(d)

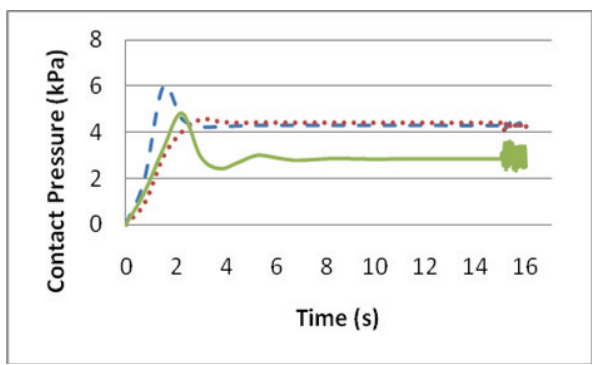

(e)

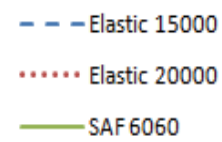

Figure 7. Variation of maximum contact pressure at location $B$ with time at various frequencies. (a) $0.1 \mathrm{~Hz}$; (b) $1 \mathrm{~Hz}$; (c) $10 \mathrm{~Hz}$; (d) $20 \mathrm{~Hz}$ and (e) $50 \mathrm{~Hz}$.

transmissibility of different cushions under vertical vibration at different frequencies. As 3D finite element model has the advantages of an accurate anatomical geometry and accuracy in performance, a 3D model representing more complicated geometry may be developed in future work.

\section{Conclusions}

This simplified simulation was designed to mimic the response of the human under the vertical vibration. Finite element analysis could evaluate the transmission of vibrations onto different seat cushions subjected to varying frequencies. From this analysis, the SAF 6060 seat cushion was found to be effective in reducing the amplitude of varying maximum contact pressure, especially for the frequency of $10-20 \mathrm{~Hz}$, belonging to the frequency range of vibration generated mostly by vehicles and aircraft. Thus, this method is useful for designing the material properties and the shape of the seat cushion for reducing the transmission of vibrations to users at a certain frequency range.

\section{Acknowledgements}

The authors would like to thank the Research Grants Council of the Hong Kong Special Administrative Region for its support of the project (PolyU 5273/07E).

\section{References}

[1] M. M. Verver, J. van Hoof, C. W. J. Oomens, J. S. H. M. Wismans and F. P. T. Baaijens, "A Finite Element Model of the Human Buttocks for Prediction of Seat Pressure Distributions," Computer Methods in Biomechanics and Biomedical Engineering, Vol. 7, No. 4, 2004, pp. $193-$ 203.

[2] D. M. Brienza, P. E. Karg, M. J. Geyer, S. Kelsey and E. Trefler, "The Relationship between Pressure Ulcer Incidence and Buttock-Seat Cushion Interface Pressure in At-Risk Elderly Wheelchair Users," Archives of Physical Medicine and Rehabilitation, Vol. 82, No. 4, 2002, pp. 529-533.

[3] J. M. Black, "Moving toward Consensus on Deep Tissue Injury and Pressure Ulcer Staging," Advances in Skin \& Wound Care: The Journal for Prevention and Healing," Vol. 18, No. 8, 2005, pp. 415-421.

[4] M. R. Bliss, "Acute Pressure Area Care: Sir James Paget's Legacy," Lancet, Vol. 339, No. 8792, 1992, pp. 221-223.

[5] M. Grujicic, B. Pandurangan, G. Arakere, W. C. Bell, T. He and X. Xie, "Seat-Cushion and Soft-Tissue Material Modeling and a Finite Element Investigation of the Seating Comfort for Passenger-Vehicle Occupants," Materials \& Design, Vol. 30, No. 10, 2009, pp. 4273-4285.

[6] E. Linder-Ganz, N. Shabshin, Y. Itzchak, Z. Yizhar, I. Siev-Ner and A. Gefen, "Strains and Stresses in SubDermal Tissues of the Buttocks are Greater in Paraplegics than in Healthy During Sitting," Journal of Biomechanics, Vol. 41, No. 3, 2008, pp. 567-580.

[7] M. Makhsous, D. Lim, R. Hendrix, J. Bankard, W. Z. Rymer and L. Fang, "Finite Element Analysis for Evaluation of Pressure Ulcer on the Buttock: Development and Vvalidation," IEEE Transactions on Neural Systems and Rehabilitation Engineering, Vol. 15, No. 4, 2007, pp. 517-525.

[8] R. Ragan, T. W. Kernozek, M. Bidar and J. W. Matheson, "Seat-Interface Pressures on Various Thicknesses of Foam Wheelchair Cushions: A Finite Modeling Approach," Archives of Physical Medicine and Rehabilitation, Vol. 83, No. 6, 2002, pp. 872-875.

[9] A. Siefert, S. Pankoke and H. P. Wölfel, "Virtual Optimisation of Car Passenger Seats: Simulation of Static and 
Dynamic Effects on Drivers' Seating Comfort," International Journal of Industrial Ergonomics, Vol. 38, No. 5-6, 2008, pp. 410-424.

[10] Q. Sun, F. Lin, L. Ruberte, E. Nam, R. Hendrix and M. Makhsous, "FE Modeling and Analysis of Compressed Human Buttock-Thigh Tissue," Proceeding of ASB 29th Annual Meeting, Georgia, 2005.

[11] B. A. Todd and J. G. Thacker, "Three-Dimensional Computer Model of the Human Buttocks, In Vivo," Journal of Rehabilitation Research, Vol. 31, No. 2, 1984, pp. 111118.

[12] E. Wagnac, C. Aubin and J. Dansereau, "A New Method to Generate a Patient-Specific Finite Element Model of the Human Buttocks," IEEE transactions on Biomedical Engineering, Vol. 55, No. 2, 2008, pp. 774-782.

[13] R. A. Cooper, "Wheelchair Selection and Configuration," Demos Medical, New York, 1998.

[14] J. L. Minkel, "Seating and Mobility Considerations for People with Spinal Cord Injury," Physical Therapy, Vol. 80, No. 7, 2000, pp. 701-709.

[15] X. Wu, S. Rakheja and P. É. Boileau, "Distribution of Human-Seat Interface Pressure on a Soft Automotive Seat under Vertical Vibration," International Journal of Industrial Ergonomics, Vol. 24, No. 5, 1999, pp. 545557.

[16] C. P. DiGiovine, R. A. Cooper, S. G. Fitzgerald, M. L. Boninger, E. J. Wolf and S. Guo, "Whole-Body Vibration During Manual Wheelchair Propulsion with Selected Seat Cushions and Back Supports," IEEE Transactions on Neural Systems and Rehabilitation Engineering, Vol. 11, No. 3, 2003, pp. 311-322.

[17] International Organization for Standardization, "ISO 2631-1: 1997, Mechanical Vibration and Shock - Evaluation of Human Exposure to Whole-Body Vibration," Switzerland, 1997.

[18] M. M. Verver, J. van Hoof, C. W. J. Oomens, N. van de Wouw and J. S. H. M. Wismans, "Estimation of Spinal Loading in Vertical Vibrations by Numerical Simulation," Clinical Biomechanics, Vol. 18, No. 9, 2003, pp. 800-811.

[19] S. Kitazaki and M. J. Griffin, "A Modal Analysis of Whole-Body Vertical Vibration Using a Finite Element Model of the Human Body," Journal of Sound and Vibration, Vol. 200, No. 1, 1997, pp. 83-103.

[20] T.-H. Kim, Y.-T. Kim and Y.-S. Yoon, "Development of a Biomechanical Model of the Human Body in a Sitting Posture with Vibration Transmissibility in the Vertical
Direction," International Journal of Industrial Ergonomics, Vol. 35, No. 9, 2005, pp. 817-829.

[21] J. Rosen and M. Arcan, "Modeling the Human Body/Seat System in a Vibration Environment," Journal of Biomechanical Engineering, Vol. 125, No. 2, 2003, pp. 223231.

[22] F. M. L. Amirouche, "Modeling of Human Reactions to Whole-body Vibration," Journal of Biomechanical Engineering, Vol. 109, No. 3, 1987, pp. 210-217.

[23] D. R. Huston, C. C. Johnson, M. A. Wood and X. Zhao, "Vibration Attenuating Characteristics of Air Filled Seat Cushions," Journal of Sound and Vibration, Vol. 222, No. 2, 1999, pp. 333-340.

[24] E. J. Wolf, M. S. R. A. Cooper, C. P. DiGiovine, M. L. Boninger and S. Guo, "Using the Absorbed Power Method to Evaluate Effectiveness of Vibration Absorption of Selected Seat Cushions During Manual Wheelchair Propulsion," Medical Engineering \& Physics, Vol. 26, No. 9, 2004, pp. 799-806.

[25] R. L. Huston, "Principles of Biomechanics," CRC Press, Boca Raton, 2009.

[26] W. Chow and E. Odell, "Deformations and Stresses in Soft Body Tissues of a Sitting Person," Journal of Biomechanical Engineering, Vol. 100, No. 2, 1978, pp. 7987.

[27] A. Lowe and R. S. Lakes, "Negative Poisson's Ratio Foam as Seat Cushion Material," Cellular Polymers, Vol. 19, No. 3, 2000, pp. 157-167.

[28] ABAQUS Version 6.9-1, "User Documentation," Dassault Systems, 2009.

[29] M. Schrodt, G. Benderoth and A. Kuhhorn, "Hyperelastic Description of Polymer Soft Foams at Finite Deformations," Technische Mechanik, Vol. 25, No. 3-4, 2005, pp. 162-173.

[30] E. Pennestrì, P. P. Valentini and L. Vita, "Comfort Analysis of Car Occupants: Comparison between Multibody and Finite Element Models," International Journal of Vehicle Systems Modelling and Testing, Vol. 1, No. $1-3,2005$, pp. 68-78

[31] C. Y. Tang and C. P. Tsui, "Method of Modeling Muscular Tissue with Active Finite Elements," U. S. Patent, The Hong Kong Polytechnic University, Kowloon (HK), 2006

[32] D. B. Chaffin, G. B. J. Andersson and B. J. Martin, “Occupational Biomechanics," Wiley-Interscience, Hoboken, 2006 . 